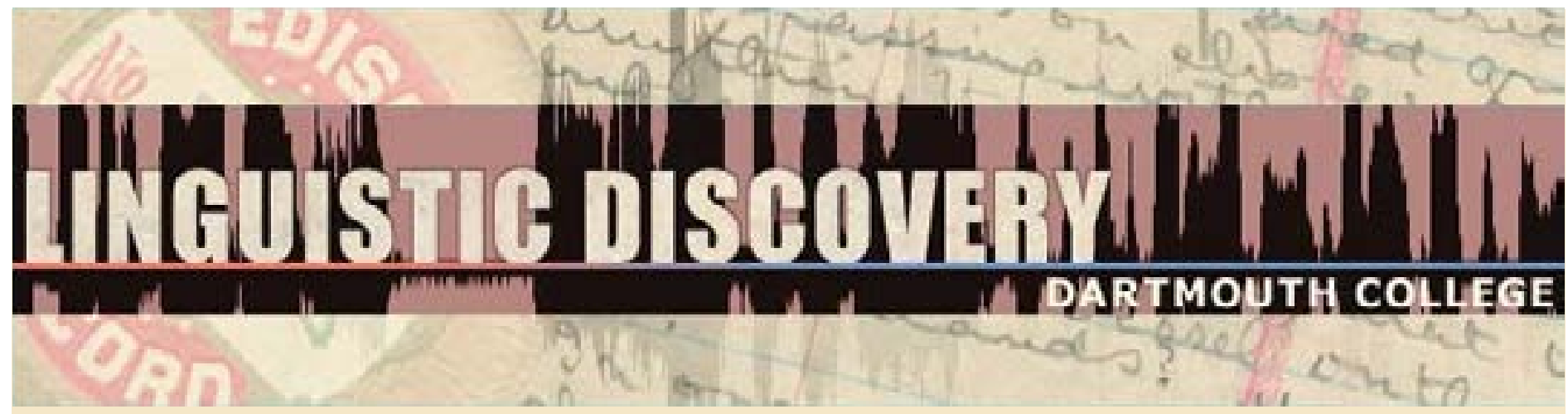

Volume 9

Issue 2 2011

\section{Finiteness in Hinuq}

Diana Forker

Max Planck Institute for Evolutionary Anthropology

doi: 10.1349/PS1.1537-0852.A.391

url: http://journals.dartmouth.edu/cgi-bin/WebObjects/ Journals.woa/1/xmlpage/1/article/391 


\title{
Finiteness in Hinuq
}

\section{Diana Forker}

\author{
Max Planck Institute for Evolutionary Anthropology
}

Hinuq (Nakh-Daghestanian language family, Caucasus, Russia) has a rich system of verbal forms. In independent/main clauses there are seven synthetic TAM forms, 20 periphrastic TAM forms, and two heterogeneous TAM forms that cannot be attributed clearly to one of these two groups. In dependent clauses there are about twenty forms that serve adverbial function, attributive function (i.e. headed and headless relative clauses) or complement function. To these forms belong suffixed forms that are traditionally called participles, adverbial participles, Infinitive and Masdar.

In this paper I analyze Hinuq verb forms and clause types with respect to categories and phenomena that have been associated with finiteness. I will explore which of the criteria actually apply to Hinuq and whether they form a cluster that could be subsumed under the notion of finiteness.

\section{Introduction}

\subsection{Finiteness in grammatical theory ${ }^{1}$}

The term 'finite', which can be traced back to the grammatical tradition of antiquity, is based on the Latin word finitus 'limited', a participle of the verb finio 'finish, limit'. This means, 'finite verb forms' are limited by a set of features, e.g. person or tense, whereas 'nonfinite verb forms' are not limited by these features.

In the linguistic literature at least three different views on finiteness can be distinguished: (i) finiteness as a morphological (i.e. mostly inflectional) property of the verb, (ii) finiteness as a distributional property of the verb, and (iii) finiteness as a property of the clause in discourse. ${ }^{2}$

The first view can be found in some descriptive grammars, e.g. in the German grammar by Eisenberg et al. (1998: 113). Verbal categories that have been taken into account for distinguishing nonfinite from finite verbs are tense and agreement marking. However, this view runs into problems because it is impossible to determine universally the morphological categories that express finiteness. Moreover, a number of languages do not express them at all on the verb, e.g. isolating languages such as Chinese, Vietnamese or Thai.

The second view relates finiteness and independence of utterances. It states that only finite verbs can occur in independent utterances. In contrast, verbs in dependent clauses are nonfinite. Nikolaeva (2007a: 3) argues that this account of finiteness may also be problematic because in a number of languages arguably nonfinite verb forms can function as the only predicate of an independent utterance. Evans (2007: 367) uses the term "insubordination" for "the conventionalized main clause use of what, on prima facie grounds, appear to be formally subordinate clauses". He mentions many examples from Australian and Indo-European

\footnotetext{
${ }^{1}$ In this section I do not aim at giving a complete overview on the term finiteness. Instead, I discuss some of its most relevant aspects, which play a role for the subsequent analysis of Hinuq. For an extensive introduction to finiteness see Nikolaeva (2007b) and also the review by Koptjevskaja-Tamm (2009).

${ }^{2}$ The list is by no means exhaustive. Sells (2007: 59) lists only (i) and (iii), but additionally two more possible uses of the term finite. Koptjevskaja-Tamm (2009: 246) also mentions (i) and (iii), and additionally syntactic finiteness. Other scholars may have other lists.
} 
languages. For example in Italian and German the infinitive can be used to express commands. Similarly, Kalinina (2001) lists several languages where participles or converbs can occur in main clauses. For instance, in Yukaghir verbal forms with the so called action nominal (imja dejstvija) suffix can be used as direct objects, as attributes of nouns and as the only predicate of independent clauses (Kalinina 2001: 47-48). Likewise, the aorist converb in Lezgian functions also as marker of the aorist tense in independent affirmative clauses (see also Haspelmath 1993: 131).

The third view seems to be the most widespread account of finiteness. It has been explicitly advocated by Givón who states that "finiteness is the systematic grammatical means used to express the degree of integration of a clause into its immediate clausal environment" (Givón 1990: 853). That means that the less finite a clause is the more it needs syntactic and semantic/ thematic integration into its context. Givón takes the prototype transitive main clause as reference point for finiteness. The more a clause deviates in its morphology, syntax and semantics/pragmatics from a transitive main clause the more it is nonfinite.

Givón (1990: 853ff) claims that finiteness is a complex, multi-featured scalar phenomenon, and lists several feature scales. He describes three scales of finiteness. The following figure presents the finiteness-scale of tense-aspect-modality and the scale of major verb-form categories, which are in principle independent of each other:

$\begin{array}{lll}\text { most finite } & \text { tense } & \text { indicative } \\ & \text { modality } & \begin{array}{l}\text { subjunctive/modal } \\ \text { aspect }\end{array} \\ & \text { negation } & \begin{array}{l}\text { infinitive } \\ \text { nominal }\end{array} \\ \text { least finite } & & \text { nomial }\end{array}$

Figure 1: Scale of finiteness

In contrast to Givón, Bisang (2001, 2007) advocates that finiteness is a discrete, binary phenomenon. His concept of finiteness relies on the notions of obligatoriness and asymmetry. Finiteness is expressed by morphosyntactic categories from which the independent status of a clause can be derived. Only languages with obligatory categories can show an asymmetry between finite and nonfinite clauses. In other words, finiteness is not a universal category. Subordinate clauses can contain more (plus-asymmetry) or fewer (minus-asymmetry) categories than the main clause. Examples of plus-asymmetry are subordination markers and differentsubject markers in switch-reference constructions. Examples of minus-asymmetry are lacking tense, person, declarative markers in subordinate clauses. Converb markers lacking absolute temporal reference, but expressing relative temporal reference are also treated by Bisang as exemplifying minus-asymmetry.

Another scholar that adheres to the third view on finiteness is Maas (2004: 361). He defines finiteness as the condition for an independent interpretation of a sentence (reference of actants, temporal anchorage, etc.).

There is no definition and no understanding of the term finiteness that all or maybe a majority of scholars would agree upon. Thus, Cristofaro (2007: 92) concludes that "it is even doubtful that finiteness and nonfiniteness may be cross-linguistically and cross-constructionally appropriate descriptive categories". Therefore, I will try to avoid the term finiteness and all related terms in my analysis of Hinuq in the body of this paper (Sections 1-3) and discuss its applicability for Hinuq only in a separate Section 4, and in the conclusion in Section 5. 
Instead, I will discuss the various morphological, syntactic, semantic and pragmatic categories and phenomena that have been related to finiteness. Morphological (inflectional) categories that have been taken into account for the definition of finiteness in the linguistic literature include:

- agreement (presence vs. absence of person, number, gender marking)

- tense (presence vs. absence of absolute tense marking, relative tense marking)

- $\mathrm{mood} / \mathrm{modality}$ (realis vs. irrealis)

- illocutionary force (declarative vs. non-declarative)

- aspect (presence vs. absence of aspect marking)

- politeness (presence vs. absence of politeness marking)

Other syntactic and semantic/pragmatic criteria employed include:

- nonfiniteness: presence of converbal, participial, infinitival, nominalizing morphology

- nonfiniteness: presence of nominal morphology, e.g. case marking or adpositions on verbs

- nonfiniteness: coding of arguments as possessors

- nonfiniteness: high referential and sequential continuity (nonfinite clauses predominantly code situations that thematically depend on the situation described in the main clause, they usually do not introduce new referents but have the same referents as the main clause)

- nonfiniteness: omissibility of overt subjects

- finiteness: syntactic opacity (anaphors in dependent finite clauses cannot be bound by antecedents in the main clause, but anaphors in dependent nonfinite clauses can be bound by main clause antecedents)

- finiteness: independent clausehood (i.e. the clause can be interpreted out of context)

- finiteness: use of topic markers

Most, but not all of these criteria are applicable to Hinuq. Section 4 will discuss in more detail all and only those categories and phenomena that are relevant for this language. In addition, I will consider evidentiality, which plays a crucial role in distinguishing dependent from independent clauses in Hinuq, but has not been taken into account so far in the literature.

Further questions that are addressed in this paper are among others: Which verbal forms occur in independent and in dependent clauses? What defines an independent clause in Hinuq? What distinguishes dependent from independent clauses?

\subsection{A short typological introduction to Hinuq}

Hinuq is the smallest of the five Tsezic languages spoken in western Daghestan (Russia) in the Caucasus, by about 600 speakers. It belongs to the Avar-Ando-Tsezic sub-branch of the NakhDaghestanian language family.

Hinuq has a gender system with five genders that are used to mark agreement between nouns in the Absolutive case and the majority of vowel-initial verbs. There are also a few vowel-initial adjectives and adverbials that show agreement with their head noun (adjectives) or the Absolutive noun of their clauses (adverbials). In addition, third person pronouns/demonstrative 
pronouns vary in form according to their gender and number. The agreement prefixes are displayed in Table 1.

\begin{tabular}{|l|l|l|l|l|l|}
\hline gender/number & I & II & III & IV & V \\
\hline SG & $\varnothing$ & $y-$ & $b-$ & $y-$ & $r-$ \\
\hline PL & $b-$ & $b-$ & $r-$ & $r-$ & $r-$ \\
\hline \multicolumn{7}{|c|}{ Table 1: Agreement prefixes }
\end{tabular}

Morphologically Hinuq is overwhelmingly concatenative and strongly suffixing (the only prefixes are the agreement prefixes). The language has Ergative case-marking.

Hinuq has postpositions. The most frequent word order is SOV, but other orders are also possible. Generally, Hinuq prefers to put the head in final position, e.g. in the noun phrase the modifiers precede the noun. The language is dependent-marking: in possessive phrases only the possessor is marked by the Genitive case; in the clause the arguments of the verb get the case marking that indicates their roles. The verb agrees with the Absolutive argument independently of the role of this argument (i.e. it can be the single argument of an intransitive clause, the patient of a transitive clause, the stimulus of an experiencer clause).

\section{Verbal Morphology}

\subsection{Introduction}

Verbs consist of a root that can be preceded by an agreement prefix and followed by various suffixes. All Hinuq verbs can be divided into four inflectional classes, depending on the rootfinal segment. Verbs having a stem final vowel cannot take the Infinitive suffix; they use the Purposive converb instead.

In the simplest case a verb can consist of the root only, e.g. nox 'come!'. Hinuq verbs do not show person agreement. Categories marked on the verb are: tense, aspect, mood, evidentiality, polarity, gender and number. Hinuq has several simple and periphrastic verb forms that express absolute past, present and future time reference, and four verb forms that express absoluterelative past time reference (Pluperfect Witnessed and Unwitnessed, Compound Future in Witnessed and Unwitnessed Past). Aspect is fused with the tense system, e.g. the Habitual Unwitnessed Past combines habitual aspect with past time reference (and the evidentiality value unwitnessed). Similarly, evidentiality is fused with certain tense forms that have past time reference. Hinuq distinguishes witnessed (i.e. the speaker has seen the event with his/her own eyes) from unwitnessed past. Unwitnessed past tense forms can usually not be used with the $1^{\text {st }}$ person. The most frequent negative suffix is -me. The categories of gender and number are fused in agreement prefixes. Furthermore, Hinuq has numerous verb forms that occur in dependent clauses (converbs, participles, etc., see Section 2.3).

The morphological make-up of verbs can be fairly complex. A simplified overview of the slots on the verb is displayed in Table 2 together with three examples. All slots in brackets are optional. 


\begin{tabular}{|l|l|l|l|l|l|l|}
\hline (agree) & root & (derivation) & (derivation) & (inflection) & (inflection) & (polarity /case) \\
\hline & $k^{\prime} i l i k$ & $-d o$ & $-t$ & & & $-m e$ \\
\hline$b-$ & $u t i$ & $-r$ & & $-a$ & $-n u$ & $-\chi$ \\
\hline$\varnothing-$ & $e d o r^{\prime}$ & & & $-y o$ & & $-m e$ \\
\hline$\varnothing-$ & $u q i$ & \multicolumn{7}{|r|}{ Table 2: A simplified morphological make-up of verbs } & \\
\hline
\end{tabular}

(1a) kilik'-do-f-me

wash-ANTIP-POT-NEG

'not able to wash'

(1b)

b-uti-r-a-nu- $\chi$

III-turn-CAUS-INF-MSD-SUB

'for making it turn'

(1c) O-edo'-yo-me

I-work-COND-NEG

'if he does not work'

\section{Ø-uqi-t-iš}

I-hide-POT-WPST

'I (masc.) hid.' or 'I could hide.'

Occasionally the negative suffix is inserted into the TAM or the participial suffix as an infix. Compare for example the affirmative Intentional Future $\varnothing$-aq'-an ('I-come-INFUT') with its negative counterpart $\varnothing$-aq'-a $<m i>n$ ('I-come-INFUT $<$ NEG $>$ '), or the negative Past Participle $\varnothing$ - $\boldsymbol{i}^{\prime}$-yo $<m e>r u$ (I-do-PST.PTCP $<\mathrm{NEG}>$ ) with the affirmative Past Participle $\varnothing$-u:-yoru (I-doPST.PTCP).

I use the verbal stem as the citation form, that is, the root plus derivational suffixes, if there are any. If a verb takes agreement prefixes this is indicated by a hyphen before the root, e.g. edo:- 'work'.

\subsection{Forms traditionally classified as "finite"}

In the indicative mood Hinuq has five synthetic TAM forms (Table 3), 20 periphrastic TAM forms (Table 4), and two TAM forms combining synthetic and analytic strategies (Table 5). Furthermore, there are two synthetic verb forms in the non-indicative mood (Table 3 ). They are all listed in the following, exemplified with the verb -i $i{ }^{\prime} i$ - 'go'. In all tables \# indicates that the relevant verb form does not exist at all (and therefore the exemplifying verb lacks it).

Note that two synthetic TAM forms (Simple Present, Simple Witnessed Past) and the Simple Unwitnessed Past are formed with the help of suffixes that are traditionally classified as

\footnotetext{
${ }^{3}$ The data presented in this paper has been taken from texts collected in the field by the author, or elicited. Elicited
} data is marked with (EL) after the English translation. 
"nonfinite", namely converbs (Imperfective converb, Perfective converb) and participles (Resultative participle). From a descriptive point of view it is possible to postulate the existence of homophonous suffixes that are however, clearly differentiable by means of their functions. This may simplify the account of the verbal system for instance in a descriptive grammar of Hinuq. But since this paper represents a critical discussion of the notion of finiteness based on data from a language that has verbal forms with a distribution contradicting current views about the morphological manifestations of finiteness, such an approach is rejected here. This decision has also consequences concerning the glosses, e.g. instead of using one label for the Simple Present and a different label for the Imperfective converb, I employ one and the same label for one and the same suffix, independently of its uses. These issues, which represent the core of the (non)finiteness discussion in Hinuq, are analyzed in detail in Section 4.2.

Some of the verbal suffixes have allomorphs whose usage depends on the last segment of the stem. For instance, the allomorphs of the Simple Present and the Imperfective converb are -ho (after stems that end with $-r$ or with a long vowel), -yo (after stems that end with a short vowel) and $-o$ (otherwise). The allomorphs of the Simple Witnessed Past and the Resultative participle are $-i s ̌$ (after consonants), $-\check{s}$ (after stem-final /i/) and $-s$ (otherwise). The Simple Unwitnessed Past and the Narrative converb have the suffixes - no (after a consonant) and - $n$ (after a vowel). In the following I will take $-o,-s$ and $-n$ as the basic forms.

\begin{tabular}{|c|c|c|}
\hline Label & affirmative & negative \\
\hline General Tense & $-i \chi ’ i$ & $-i \chi ' i-m e$ \\
\hline Simple Present & $-i \chi ’ i-y o$ & \# \\
\hline Simple Witnessed Past & $-i \chi \dddot{i}-\check{S}$ & $-i \chi i-\check{S}-m e$ \\
\hline Definite Future & $-i \chi^{\prime}-a s$ & $\#$ \\
\hline Intentional Future & $-i \chi^{\prime}-a n$ & $-i \chi^{\prime}-a m i n$ \\
\hline Imperative & $-1 \chi_{i} i$ & $-i \chi i-y o m$ \\
\hline Optative & $-i x_{i-\lambda o}$ & $-i \chi i-y o m-\chi_{o}$ \\
\hline
\end{tabular}

The General tense is used when referring to the future or when reporting general statements that do not refer to a certain moment in time, e.g.

$$
\begin{array}{llcc}
\text { keč } & \text { caxed-mez } & \text { de } & \varnothing \text {-iči-l-me } \\
\text { song write.POT-PURP.NEG } & 1 \mathrm{SG} & \text { I-be-POT-NEG } \\
\text { 'I (masc.) am not able not to write poems.' }
\end{array}
$$

The great majority of transitive verbs have the Imperative suffix $-o$, whereas intransitive verbs use their stem as Imperative (for examples see (17) in Section 3.6 and (26) in Section 4.3.2).

Two of the synthetic TAM forms do not have a negative form (Table 3 ). If clauses containing these forms are negated, other periphrastic TAM forms must be used (the Compound Present if the Simple Present is negated; the Compound Future or the Intentional Future if the Definite Future is negated). Two of the synthetic TAM forms can be analyzed as homophonous with verbal forms used in dependent clauses: the Simple Present is homophonous with the Imperfective converb, and the Simple Witnessed Past is homophonous with the Resultative 
Participle. Another alternative analysis could posit that these are not two homophonous suffixes, but in fact one suffix with different but related functions. See Section 4.2 for a detailed discussion of these suffixes.

\begin{tabular}{|c|c|c|}
\hline Label & affirmative & negative \\
\hline \multicolumn{3}{|c|}{ Present time reference } \\
\hline Compound Present & -i丸'i-yo got & $-i \chi i-y o$ gom \\
\hline Habitual Present & $-i \chi i-\chi$ os got & $-i \chi i-\chi$ os gom \\
\hline Resultative Present & $-i x_{i-\check{S}} \operatorname{got}$ & $-i \chi \grave{i}-\check{s}$ gom \\
\hline Intentional Present & $-i \chi^{\prime}-a r u$ got & 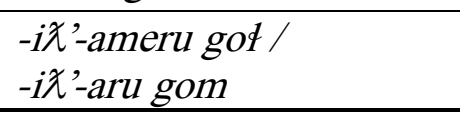 \\
\hline \multicolumn{3}{|c|}{ Past time reference, witnessed by speaker } \\
\hline Compound Witnessed Past & -ið’i-yo zoq’wes & -ið’i-yo zoq’wesme \\
\hline Habitual Witnessed Past & 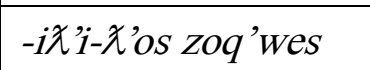 & 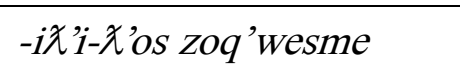 \\
\hline $\begin{array}{l}\text { Compound Habitual } \\
\text { Witnessed Past }\end{array}$ & -ið’i-yo zoq'wes got & -iх’i-yo zoq'wes gom \\
\hline Resultative Witnessed Past & -ið’i-š zoq’wes & -ið’i-š zoq’wesme \\
\hline Pluperfect Witnessed Past & -ið’i-n zoq’wes & -ið’i-n zoq’wesme \\
\hline 'Still not' Witnessed Past & $\#$ & -ix'-anu zoq'wes \\
\hline Intentional Witnessed Past & -ið'-aru zoq'wes & $\begin{array}{l}\text {-iХ'-ameru zoq'wes / } \\
i \chi \text { '-aru zoq'wesme }\end{array}$ \\
\hline $\begin{array}{l}\text { Compound Future in } \\
\text { Witnessed Past }\end{array}$ & $-i x^{\prime}-a$ zoq'wes & $-i x^{\prime}-a$ zoq'wesme \\
\hline \multicolumn{3}{|c|}{ Past time reference, not witnessed by speaker } \\
\hline $\begin{array}{l}\text { Compound Unwitnessed } \\
\text { Past }\end{array}$ & -ið’i-yo zoq’wen & -ið'i-yo zoq’wen gom \\
\hline Habitual Unwitnessed Past & $-i \chi i-\chi ’ o s z o q ’ w e n$ & 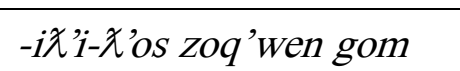 \\
\hline $\begin{array}{l}\text { Resultative Unwitnessed } \\
\text { Past }\end{array}$ & $-i \chi ’$ i-š zoq'wen & $-i \chi ’-\check{S} z o q$ 'wen gom \\
\hline $\begin{array}{l}\text { Pluperfect Unwitnessed } \\
\text { Past }\end{array}$ & -ið’i-n zoq’wen & -iХ’i-n zoq’wen gom \\
\hline $\begin{array}{l}\text { 'Still not' Unwitnessed } \\
\text { Past }\end{array}$ & \# & -ix'-anu zoq'wen \\
\hline $\begin{array}{l}\text { Intentional Unwitnessed } \\
\text { Past }\end{array}$ & -ið'-aru zoq'wen & 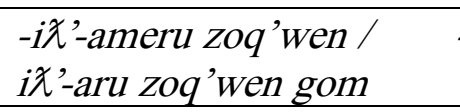 \\
\hline $\begin{array}{l}\text { Compound Future in } \\
\text { Unwitnessed Past }\end{array}$ & $-i \chi^{\prime}-a z^{\prime}{ }^{\prime}{ }^{\prime} w e n$ & -ix’-a zoq’wen gom \\
\hline \multicolumn{3}{|c|}{ Future time reference } \\
\hline Compound Future & $-i x^{\prime}-a$ got & $-i x^{\prime}-a$ gom \\
\hline
\end{tabular}


Periphrastic TAM forms are built up by combining one of seven verbal forms that otherwise occurs only in subordinate clauses together with a form of the copula (got, zoq'wes or zoq'wen). These seven verbal forms are: Imperfective converb, Narrative converb, Resultative Participle, Habitual Participle, Infinitive, Masdar and the Intentional form. Periphrastic verb forms that are built by using the auxiliary zoq'we-s 'be-WPST' (or zoq'wes got in one case) have the evidentiality meaning 'witnessed by the speaker', e.g. the following sentence in the Compound Witnessed Past is part of the memories of a speaker who talks about his childhood:

\begin{tabular}{|c|c|c|}
\hline ulu-za-ð’o & q'ay-be & $r-i q^{\prime}-o$ \\
\hline rse-PL.OBL-SPR & thing-PL & NPL-bring-IPFV.CVB \\
\hline
\end{tabular}

'They brought the things on horses.'

In contrast, forms containing zoq'we-n 'be-UWPST' have the evidentiality meaning 'not witnessed by the speaker' and are predominantly used when telling fairy tales or legends, e.g. the Compound Unwitnessed Past used in a fairy tale:

$$
\begin{array}{lllllll}
\text { amma } & \text { haw } & \text { ked } & \text { y-uq'er-tow } & \text { y-aq'o } & \text { zoq'we-n } & \text { gom } \\
\text { but } & \text { that } & \text { girl(II) } & \text { II-heal-PART } & \text { II-come-IPFV.CVB } & \text { be-UwPST } & \text { be.NEG }
\end{array}
$$

'(Many doctors and other people came), but they did not heal the girl.'

Note that the TAM forms involving the Masdar can only contain affirmative copula forms, but they have a negative semantics (Section 4.2.4).

In addition, there are two verbal forms that are heterogeneous because they can be used with or without a copula: the Simple Unwitnessed Past, which is always periphrastic when negated, and simple when affirmative, and the 'Still not' Present, which can be used with or without a copula (see 4.2.4 for an example).

\begin{tabular}{|l|l|l|}
\hline Label & affirmative & negative \\
\hline Simple Unwitnessed Past & $-i \chi$ 'i-n & $-i \chi$ ' - -n gom \\
\hline 'Still not' Present & $\#$ & $-i \chi$ '-anu (goł) \\
\hline \multicolumn{2}{|l}{ Table 5: Heterogeneous TAM forms }
\end{tabular}

\subsection{Forms traditionally classified as "nonfinite"}

As typical for Nakh-Daghestanian languages, Hinuq has a great number of verb forms that occur in subordinate clauses. These verb forms are called converbs, participles, Infinitive and Masdar (see Table 6 below). Most of them are formed by adding a suffix to the verbal stem, but a few verbal forms used in subordinate clauses are periphrastic.

The verb forms displayed in Table 6 serve either an adverbial function, an attributive function (i.e. headed and headless relative clauses) or a complement function. See 3.6 and 4.2.1 for more details and examples. 


\begin{tabular}{|c|c|c|}
\hline Label & Affirmative & Negative \\
\hline \multicolumn{3}{|c|}{ Converbs } \\
\hline Posterior Converb & $-i \chi i-\chi x^{\prime} o r$ & \# \\
\hline Terminative Converb & $-i \chi^{\prime}-a-\check{c} e$ & $\#$ \\
\hline First Simultaneous Converb & $-i \chi i-\chi o$ & 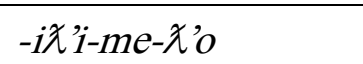 \\
\hline Second Simultaneous Converb & $-i x^{2}-a-\not i$ & $-i \chi^{\prime}-a-m e-\not i$ \\
\hline Progressive Converb & $-i \chi i-y o-i c ̌ i n$ & $\#$ \\
\hline $\begin{array}{l}\text { Reduplicated Narrative } \\
\text { Converb }\end{array}$ & $-i \chi^{\prime}-a n(n o)-i \chi^{\prime} i-n$ & $\#$ \\
\hline Simple Anterior Converb & $-i \chi i-n o s$ & \# \\
\hline Immediate Anterior Converb & $-i \chi_{i-y o r u n}$ & $\#$ \\
\hline Narrative Converb & $-i \chi^{\prime} i-n$ & $\#$ \\
\hline Imperfective Converb & $-i \chi_{i-y o}$ & \# \\
\hline Conditional Converb & $-i x^{\prime} i-y o$ & -iðі-уо-me \\
\hline Concessive Converb & $-i \chi_{i-o n}(o)$ & -iði-yon-me \\
\hline Purposive & $-i \chi i-y a z$ & $-i \chi \ddot{i}-m e-Z$ \\
\hline \multicolumn{3}{|c|}{ Participles } \\
\hline Local Participle & $-i \chi i-y a$ & -iði-ya-me \\
\hline Present Participle & -iði-yo goła & -iði-yo goуо-me-ru \\
\hline Past Participle & $-i \chi{ }_{i-y o r u}$ & $-i \chi \ddot{i}-y o-m e-r u$ \\
\hline Habitual Participle & $-i \chi i-\chi$ 'os & -ixi-me-え’os \\
\hline Resultative Participle & $-i \chi i-\check{S}$ & $-i \chi \dddot{i}-\check{S}-m e$ \\
\hline \multicolumn{3}{|c|}{ Other verb forms } \\
\hline Nominalized Infinitive & $-i \chi^{\prime}-a-l i$ & $\#$ \\
\hline Masdar & $-i \chi^{\prime}-a-n u$ & $\#$ \\
\hline Infinitive & $-i \chi^{\prime}-a$ & $\#$ \\
\hline
\end{tabular}

Table 6: Converbs, participles and other "nonfinite" verb forms

\section{Syntax of the Clause}

Main clauses in Hinuq can be nominal clauses and verbal clauses. Besides, there is a minor clause type headed by an adverb. Main verbal clauses can be headed by all verbal forms listed in Tables 3-6. There are three types of subordinate clauses: complement clauses, adverbial clauses and relative clauses. This section will briefly discuss all clause types.

\subsection{Copula clauses}

Both the subject and the predicate can be in the Absolutive case (5a) or the predicative can take various case markers, according to its function $(5 b)$. The predicate can be a proper name, a noun 
phrase, a pronoun or an adjective. The copula occurs obligatorily; often but not always in clausefinal position (5a).

$$
\begin{aligned}
& \text { Muhamad Nabi po?et got } \\
& \text { Mohamed Nabi poet be } \\
& \text { 'Mohamed Nabi is a poet.' }
\end{aligned}
$$

$$
\begin{aligned}
& \text { kabaxu-ni gulu zoq'we-s debe } \\
& \text { black-PART horse be-WPST 2SG.GEN1 } \\
& \text { 'The black horse was yours.' }
\end{aligned}
$$

\begin{tabular}{|c|c|c|c|c|c|}
\hline [nagaћ & $z o$ & hibału & unti-mo-qo-s & hezzor & Ø-uti-yo-me] \\
\hline if & REFL & this.OBL & disease-OBL-AT-ABL1 & back & I-turn-COND-NEG \\
\hline & mežu-qo & inat & & & \\
\hline 1SG.GEN1 & 2PL.OBL-AT & order & & & \\
\hline
\end{tabular}

In non-indicative copula clauses with present time reference, especially in short interrogative clauses, the copula can be left out, e.g.

$$
\begin{aligned}
& \text { obu, ni hago uži? } \\
& \text { father where that boy } \\
& \text { 'Father, where is that boy?' }
\end{aligned}
$$

'If I (masc.) do not come back from the disease, this is my order for you:...

\subsection{Non-indicative verbal clauses}

Major non-indicative forms are the Imperative (7), the Optative and the Irrealis conditional (8). Imperatives and Optatives show the same agreement properties as non-indicative forms (i.e. gender agreement with the Absolutive argument). Although they are commonly used without overt subjects, there are no restrictions on co-occurrence with subjects (7). The major difference between Imperatives and Optatives on the one hand and indicative verb forms on the other hand is the form of the negative suffix which at least diachronically differs from the usual negative suffix $-m e$. Besides, Imperatives are only used with $2^{\text {nd }}$ person. The Imperative is identical to the General Tense with a number of intransitive verbs. ${ }^{4}$ The Optative occurs with all persons and numbers.

$$
\begin{array}{lllll}
\text { hoboži } & \text { me } & \varnothing \text {-uti } & \text { di-Žo } & \text { moqoli-ð’o-S } \\
\text { now } & \text { 2SG } & \text { I-go.down } & \text { 1SG.OBL-GEN2 } & \text { back-SPR-ABL1 } \\
\text { 'Now you (masc.) come down from my back!' }
\end{array}
$$

\footnotetext{
${ }^{4}$ But intransitive verbs with a stem-final vowel bear stress on the final vowel in the General tense, but not in the Imperative (e.g. - $i \Varangle i-$ 'go.GT' vs. - 1 ‘ $i$ - 'go.IMP', see Table 3 in Section 2.2 above).
} 
In the protasis of irrealis conditional clauses a TAM form is combined with the particle q'ede. In the apodosis either the lexical verb in the General tense followed by a special form of the copula (goti, example (8a)) or one of the future in the past forms is used (8b).

\begin{tabular}{|c|c|c|c|c|c|}
\hline $\begin{array}{l}\text { hut } \\
\text { yesterday }\end{array}$ & $\begin{array}{l}u \check{Z} i-\check{Z} \\
\text { boy-DAT }\end{array}$ & $\begin{array}{l}\text { mecxer } \\
\text { money(III) }\end{array}$ & $\begin{array}{l}b \text {-aši-š } \\
\text { III-get-WPST }\end{array}$ & $\begin{array}{l}\text { q'ede, } \\
\text { IRR }\end{array}$ & $\begin{array}{l}\text { hayłoy } \\
\text { 3SG.MASC.ERG }\end{array}$ \\
\hline kede-Z & k'oћlo & $b-u x$ & goti & & \\
\hline
\end{tabular}

'If the boy had gotten the money yesterday, he would have bought a ball for the girl.' (EL)

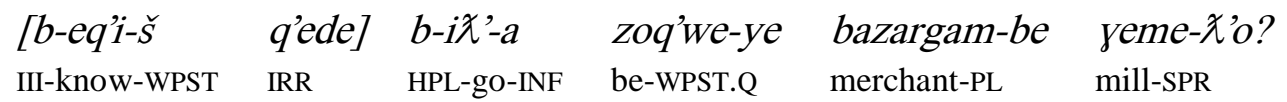

'If they had known this, would the merchants have gone to the mill?'

Realis conditional clauses are expressed by using the Conditional converb in the protasis (see Table 6). In the apodosis of these sentences various TAM forms can occur, e.g. the General tense, the Simple Present or the Compound Future.

\subsection{Indicative verbal clauses}

Simple indicative verbal clauses can be headed by a synthetic or a periphrastic verb. Major clause types are intransitive (9a), transitive (9b) and experiencer clauses (9c). In an intransitive clause the single argument of the verb is in the Absolutive case and the verb agrees with it in gender and number, if it has an agreement prefix. In the transitive construction the agent is in the Ergative case, the patient in the Absolutive case and the verb agrees with the patient (if it has an agreement prefix). In the experiencer construction the experiencer is in the Dative case and the stimulus in the Absolutive case. The verb agrees with the stimulus (if it has an agreement prefix).

$$
\begin{aligned}
& \text { haw miskinaw-ni ked y-iži-n hayłoy } \\
& \text { that poor-PART girl(II) II-take-UWPST 3SG.MASC.ERG } \\
& \text { 'He took this poor girl.' }
\end{aligned}
$$

$\begin{array}{lllllll}\text { (9c) hače-tow } & \text { bercinaw } & \text { žied } & \text { diž } & \text { rek’we } & \varnothing \text {-ike-n } & \text { zoq'we-s-me } \\ \text { how.much-PART } & \text { beautiful } & \text { yet } & \text { 1SG.DAT } & \text { man } & \text { I-see-PFV.CVB } & \text { be-WPST }\end{array}$

'I did not see such a handsome man.' 


\subsection{A minor sentence type}

There is a special construction with the adverb behula 'possible', a loan from Avar, plus a verb in the Infinitive as the predicate of the clause. These clauses occur on their own and express future possibilities, that is, events that might occur in the future.

\begin{tabular}{|c|c|c|}
\hline $\begin{array}{l}\text { gilux'os } \\
\text { suddenly }\end{array}$ & $\begin{array}{l}b-O X-a \\
\text { III-leave-INF }\end{array}$ & $\begin{array}{l}\text { behula } \\
\text { possible }\end{array}$ \\
\hline
\end{tabular}

'He said it is possible that it (i.e. the monkey) suddenly escapes.'

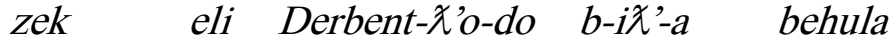

$$
\begin{aligned}
& \text { tomorrow 1PL Derbent-SPR-DIR HPL-go-INF possible } \\
& \text { 'It is possible that we go to Derbent tomorrow.' (EL) }
\end{aligned}
$$

\subsection{Complement clauses}

Bare indicative forms are generally not used in dependent clauses. They must be marked by some clitic in order to occur in complement clauses. This can either be the quotative enclitic, which is predominantly but not exclusively used with verbs of speech (11a), (24a), (25) or the Abstract enclitic (11b), (13), (28). The latter enclitic is used in the formation of abstract nouns from nouns, participles, adverbs and adjectives. ${ }^{5}$ The only exceptions are direct speech and complements of the perception verbs -ike- 'see' and toq- 'hear' (11c). That is, complements of 'see' and 'hear' can, but need not contain the Abstract enclitic. Other verb forms are not allowed in complement clauses of these two predicates.

$$
\begin{array}{lllll}
u Z ̌ i & \varnothing \text { - } u \chi^{\prime}-o & \text { [zo } & \text { boc'e- } z & \varnothing \text {-ik-o- } \chi \text { en }] \\
\text { boy(I) } & \text { I-be.afraid-PRS } & \text { REFL.SG } & \text { wolf-DAT } & \text { I-see-PRS-QUOT }
\end{array}
$$

'The boy fears that the wolf sees him.' (EL)

$$
\begin{array}{lllll}
\text { hayłoy } & {[\chi \text { erba-be }} & b \text {-aq’e-s-1i] } & \text { diqo } & \text { c'ałer-iš-me } \\
\text { 3SG.MASC.ERG } & \text { guest-PL } & \text { HPL-come-RES.PTCP-ABST } & \text { 1SG.LAT } & \text { tell-wPST-NEG }
\end{array}
$$

'He did not tell me that the guest came.' (EL)

$$
\begin{array}{lllll}
\text { hayłoz } & \text { toq-o, } & \text { iyo-y } & \text { ac } & \text { y-ayi-yo } \\
\text { 3SG.MASC.DAT } & \text { hear-PRS } & \text { mother-ERG } & \text { door(IV) } & \text { IV-open-PRS }
\end{array}
$$

'He hears that mother opens the door.' (EL)

Other forms frequently occurring in complement clauses are the Infinitive (12b) and the Purposive converb (12a, b). Both forms are interchangeable, but the Purposive converb is

\footnotetext{
${ }^{5}$ Examples of such derived abstract nouns are bičišs $f i$ 'living' (from the verb -iči- 'be') and xodbaru- $f i$ 'marriage' (from the compound noun xod-baru 'married couple, lit. 'husband-wife'). However, the suffix occurs predominantly on loan words, e.g. axran- $f i$ 'guarding' (from Russ. oxrana 'guarding'), or bac'ad- $f i$ 'cleanness' (from Avar bacad 'cleanly').
} 
somewhat more common. The subject of the Infinitival/Purposive converb complement clause is generally omitted under referential identity with the subject of the main clause (12a), but in principle it is possible to preserve it in both clauses (12b). If the main clause subject is not identical to the Infinitival/Purposive converb clause subject, then both subjects occur overtly (12c).

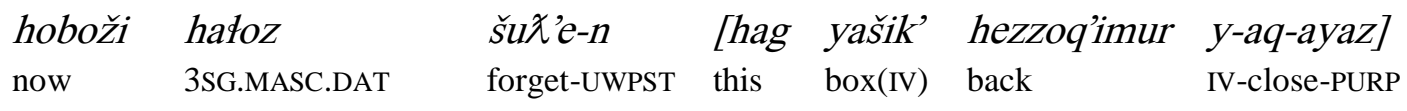

'He forgot to close the box.'

\begin{tabular}{|c|c|c|c|c|}
\hline $\begin{array}{l}\text { hayłoz }_{i} \\
\text { he.DAT }\end{array}$ & $\begin{array}{l}\text { koð'-o } \\
\text { be.able-IPFV.CVB }\end{array}$ & $\begin{array}{l}\text { gom } \\
\text { be.NEG }\end{array}$ & $\begin{array}{l}{\left[Z O_{i}\right.} \\
\text { REFL.SG }\end{array}$ & $\begin{array}{l}\text { kwezera-za- } \chi \text { 'o-r } \\
\text { hand.OBL-OBL.PL-SPR-LAT }\end{array}$ \\
\hline & /Ø-ič-ayaz] & & & \\
\hline I-stand-INF & / I-stand-PURP & & & \\
\hline
\end{tabular}

'He cannot stand on the hands.' (EL)

$\begin{array}{llllll}\text { hałoz } & \text { r-eti-yo } & \text { [de } & \text { kayat cax-a } & \text { / cax-ayaz] } \\ \text { 3SG.MASC.DAT } & \text { NPL-want-PRS } & \text { 1SG.ERG } & \text { letter } & \text { write-INF } & \text { / write-PURP }\end{array}$

'He wants me to write a letter.' (EL)

Some complements are formed with the Habitual Participle plus the Abstract enclitic. This type of complement clause occurs with verbs referring to knowledge. The following example represents a complement clause embedded into a converb clause.

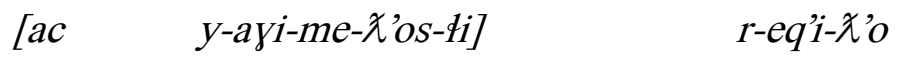

$$
\begin{aligned}
& \text { door(IV) IV-open-NEG-HAB.PTCP -ABST V-know-SIM } \\
& \text { 'when (he) understood, that (she) would not open the door...' }
\end{aligned}
$$

Complements can also be nominalized and take case suffixes. This type of complement clause is very rare and occurs only with a few verbs, e.g. boži -iq- 'believe' and šak -iq- 'doubt'. Nominalized verb forms occurring in complement clauses are the Past Participle or the Masdar (14).

$$
\begin{aligned}
& \text { de šak Ø-iqqo [zekes Jwede r-egi r-iq-a-nu-え’o] } \\
& 1 \mathrm{SG} \text { doubtful I-be.PRS tomorrow.GEN1 day(V) V-good V-be-INF-MSD-SPR }
\end{aligned}
$$

'I doubt that tomorrow will be good weather (lit. a good day).' (EL)

The verbs faq'e- (intr.) and laq'er- (trans.) 'finish', 'end' behave exceptionally because their complements are always and only marked with the Narrative converb suffix.

$$
\begin{aligned}
& \text { [kak r-u'-n] taq'e-y丸'o } \\
& \text { prayer(v) V-do-PFV.CVB end-SIM } \\
& \text { 'when praying ends...' }
\end{aligned}
$$




\subsection{Adverbial clauses (Converb clauses)}

Hinuq has eight specialized temporal converbs that express temporal relations (Table 6). Their suffixes are mostly diachronically complex, containing for example a case suffix (e.g. the Posterior Converb ends with the Lative $-r$ ) or an enclitic (e.g. the second Simultaneous Converb contains the Abstract enclitic - $4 i$, and the Immediate Anterior Converb the coordinative enclitic $n)$.

Hinuq has two contextual converbs that are not only used in adverbial clauses but also for the formation of periphrastic TAM forms (see Table 4 in Section 2.2). Furthermore, there are three specialized non-temporal converbs expressing condition, concession (16) and purpose. Only the converbs expressing simultaneity and the specialized non-temporal converbs have negative forms.

\begin{tabular}{|c|c|c|c|c|}
\hline $\begin{array}{l}\text { [hato } \\
\text { this.OBL }\end{array}$ & $\begin{array}{l}\text { sumka-n } \\
\text { bag-IN }\end{array}$ & & хети & gor-onc \\
\hline
\end{tabular}

'Even if you put a stone into this bag, it will not tear.' (EL)

The Purposive converb and the Narrative converb are also used in complement clauses (see (12ac) in Section 3.5).

Not only converbs, but also three participles (the Local Participle, the Present Participle, and the Past Participle) occur in adverbial clauses. The Local Participle is used in adverbial clauses expressing local and temporal circumstances (and in relative clauses with a locative meaning). The Present Participle has the temporal meaning of simultaneity in adverbial clauses. The Past Participle serves not only as the base for the Immediate Anterior Converb, but occurs also in temporal adverbial clauses with the meaning 'when', in non-temporal adverbial clauses with the meaning 'as' (17), and for the expression of causes. In order to achieve the non-temporal meanings local case suffixes must be added to the Past Participle.

$$
\begin{array}{lll}
\text { [debez } & \text { r-eq'i-yoru-ho-r }] & r \text { - } u w-o ! \\
\text { 2SG.DAT } & \text { V-know-PST.PTCP-ILOC-LAT } & \text { V-do-IMP } \\
\text { 'Do as you like (lit. know, can).' } & \text { (EL) }
\end{array}
$$

\subsection{Relative clauses}

The most common way of forming a relative clause is the use of participles as the predicate of the relative clause. Sentence (18) presents an example with the Present Participle. A large number of semantic roles can be relativized (e.g. agent, patient, recipient, experiencer, instrument, location, etc.). There is usually no indication of the role that the referent of the head noun has in the relative clause (gap strategy).

$$
\begin{array}{lllll}
b \text {-aq'o } & \text { hayło-de- } r & \text { hibaw } & \text { [hało-y } & \text { kiki-yo } \\
\text { III-come-PRS } & \text { 3SG.MASC.OBL-ALOC-LAT } & \text { that } & \text { 3SG.MASC.OBL-ERG } & \text { feed-IPFV.CVB }
\end{array}
$$


gota] coy

be.PTCP eagle(III)

'To him comes the eagle that he had fed.'

\section{Finiteness in Hinuq}

\subsection{Verbal forms and clause types}

The distribution of verbal suffixes and clause types is summarized in Table 7. Optionality is indicated by parentheses. Three suffixes $(-o,-n,-s)$ occur in both independent and dependent clauses with differing, but related meanings/functions. However, as mentioned in Section 2.2, they are not regarded as different, though homophonous suffixes, but rather as suffixes occurring in different functions. Therefore, each of the three suffixes is assigned only one label in the glosses (i.e. $-o$ is glossed with IPFV.CVB, $-n$ is glossed with PFV.CVB and $-s$ is glossed with RES.PTCP).

\begin{tabular}{|c|c|c|c|c|c|}
\hline clause type & indeper & nt clauses & dependent cl & Ises & \\
\hline verbal suffixes & $\begin{array}{l}\text { simple } \\
\text { verb }\end{array}$ & $\begin{array}{l}\text { periphrastic } \\
\text { verb }\end{array}$ & $\begin{array}{l}\text { complement } \\
\text { clauses }\end{array}$ & $\begin{array}{l}\text { adverbial } \\
\text { clauses }\end{array}$ & $\begin{array}{l}\text { relative } \\
\text { clauses }\end{array}$ \\
\hline $\begin{array}{l}\text { Imperfective converb } \\
(-o /-y o /-h o)\end{array}$ & $\checkmark$ & $\checkmark+$ be & $\begin{array}{l}\checkmark \\
(+ \text { enclitic })\end{array}$ & $\checkmark$ & $\checkmark+\operatorname{gota}^{6}$ \\
\hline $\begin{array}{l}\text { Perfective converb } \\
(-n /-n o)\end{array}$ & $\checkmark$ & $\checkmark+$ be & $\checkmark$ & $\checkmark$ & \\
\hline $\begin{array}{l}\text { Resultative participle } \\
(-s /-\check{S} /-i \check{S})\end{array}$ & $\checkmark$ & $\checkmark+$ be & $\checkmark+$ enclitic & & $\checkmark$ \\
\hline Masdar $(-n u)$ & $\checkmark$ & $\checkmark+$ be & $\checkmark(+$ case $)$ & & $\checkmark$ \\
\hline Habitual participle $(-\chi o s)$ & & $\checkmark+$ be & $\checkmark+$ enclitic & & $\checkmark$ \\
\hline Infinitive $(-a)$ & & $\checkmark+$ be & $\checkmark$ & $\checkmark+-\check{c} e$ & $\checkmark+-l i$ \\
\hline $\begin{array}{l}\text { Local participle }(-y a), \\
\text { Past participle }(-o r u)(\mathrm{v})\end{array}$ & & & & $\begin{array}{l}\checkmark \\
(+-n / \text { case })\end{array}$ & $\checkmark$ \\
\hline $\begin{array}{l}\text { Definite Future (-as), } \\
\text { Intentional Future }(-a n) \text {, } \\
\text { Imperative } \emptyset /-o) \text {, } \\
\text { Optative }\left(-\chi^{\prime} o\right)(\mathrm{i})\end{array}$ & $\checkmark$ & & & & \\
\hline Intentional (-aru) (vi) & & $\checkmark+$ be & & & \\
\hline specialized converbs (iv) & & & & $\checkmark$ & \\
\hline
\end{tabular}

Table 7: The distribution of verbal suffixes and clause types

There is no one-to-one match between verb suffixes/forms and clause types, i.e. the majority of the verb forms occur in more than one clause type. There are no verbal forms exclusively specialized for complement clauses or relative clauses. All verb forms allow for overt subjects. All verb forms agree with the absolutive argument of their clause. ${ }^{7}$

\footnotetext{
${ }^{6}$ It is not a property of the Imperfective converb alone that it can be used in relative clauses, but rather of the combination of the Imperfective converb with the participle of the copula gota.

${ }^{7}$ Complement-taking verbs with the complement clause in direct object position take either the agreement prefix $r$ (gender V/ non-human plural) or they agree with the Absolutive argument of the embedded clause (Section 4.3.4).
} 
When looking in more detail at the distribution of the verbal suffixes across clause types the following picture arises

(i) There are four suffixes that are used only in simple affirmative TAM forms, two of them in indicative forms (Definite Future, Intentional Future), one in the Imperative and one in the Optative. These forms lack either a negative counterpart, or the negative form is morphologically somewhat arbitrary (i.e. at least synchronically it is not formed with the negative suffix -me, which is used in all other verbal TAM suffixes). Suffixes of this group can be regarded as the Hinuq prototype of suffixes expressing 'finiteness'. The group is exemplified by three sentences with the Imperative, (7), (17) and (26).

(ii) There are four suffixes that are used in dependent clauses, and also in independent clauses with or without an additional auxiliary (Imperfective converb, Perfective converb, Resultative participle and Masdar, see 4.2)

(iii) There are two suffixes that are used in dependent clauses, and also in independent clauses always in combination with an auxiliary (Habitual Participle and Infinitive). Examples are (13) and (28) for the Habitual Participle and (8b), (10a, b), (12b, c), (16) and (39a) for the Infinitive.

(iv) There are a number of suffixes used only in adverbial clauses, e.g. the Posterior Converb, the Simultaneous converbs or the Concessive converb. These suffixes mostly lack a negative counterpart. Examples can be found in (15) and (16).

(v) Two suffixes are exclusively used for the formation of verb forms occurring in adverbial and relative clauses (Local Participle, Past Participle) (17).

(vi) There is one suffix (the Intentional Participle -aru) that is used only in independent clauses together with an auxiliary. It is not used as the head of dependent clauses.

This picture is familiar from other Nakh-Daghestanian languages (see Kalinina and Sumbatova 2007 for Icari Dargwa, Bagwalal and Tsakhur, Kalinina 2001 for Avar and Lezgian and Creissels 2009 for Akhvakh).

\subsection{Suffixes of group (ii)}

One of the most remarkable features of the Hinuq verbal system is the existence of the suffixes of group (ii) that are used both in dependent and independent clauses, in simple and periphrastic verbal forms. The first three of these suffixes, $-o,-n$ and $-s$, are among the most frequently used verb forms. On the contrary, the Masdar is only occasionally employed.

As has been mentioned before (Section 2.2) these suffixes could be treated as being different suffixes with different functions that just happen to have the same form. However, I want to argue that the suffixes represent only one morpheme each, but occur in more than one function.

\subsubsection{The Imperfective converb (-o)}

The Imperfective converb suffix - $o$ has the most functions. It occurs in five different clause types: (i) in independent clauses as the Simple Present, without any additional auxiliary (11a, c), (12c), (14), (18), (24a), (26), etc.; (ii) in periphrastic TAM forms of independent clauses, e.g. (3), (4), (12b), (19), (27a); (iii) in complement clauses together with a clitic, e.g. with the quotation 
clitic (11a); (iv) in adverbial clauses as Imperfective converb (24a); and in relative clauses in combination with gota, the affirmative participle of the copula (18), (29b).

The various occurrences of $-o$ are usually formally distinct due to an additional auxiliary, e.g. the participle goła occurs only in dependent clauses (relative clauses and adverbial clauses), and thus also the combination of - $o$ and goła always heads a dependent clause. But the occurrences of $-o$ in the Simple Present and as Imperfective converb in adverbial clauses can only functionally be distinguished from each other. That means, verbs in the Simple Present have absolute present time reference, whereas verbs used as Imperfective converbs do not express absolute present time reference, but relative present time reference and imperfective aspect (see example (24a) in Section 4.3.1). I regard the occurrence of - $o$ as Imperfective converb as basic, from which the occurrence of the same suffix in independent clauses with present time reference can be implied. That is, if a converb is used in an independent clause it must have some type of absolute time reference. For a converb with an imperfective aspectual meaning it is natural to arrive at a present time reference in independent clauses since the present is usually imperfective. Thus, the occurrence of - $o$ as Simple Present is a consequence of its use in independent clauses rather than an independent development of the converb in this position. ${ }^{8}$

\subsubsection{The Perfective converb -n}

The Perfective converb suffix $-n$ occurs in four different clause types: (i) as Simple Unwitnessed Past in independent affirmative main clauses (9b), (10a), (12a); (ii) in periphrastic verb forms heading independent clauses, e.g. in the Pluperfect Witnessed Past (9c); in complement clauses (15), (24b); and in adverbial clauses (19), (27b):

\begin{tabular}{|c|c|c|c|}
\hline $\begin{array}{l}\text { hayło } \\
\text { that.oBL }\end{array}$ & $\begin{array}{l}\text { rek'u-y } \\
\operatorname{man}(\mathrm{I}) . \mathrm{OBL}-\mathrm{ERG}\end{array}$ & $\begin{array}{l}{[\chi \text { emo- } \chi o-n o} \\
\text { stairway-SPR-and }\end{array}$ & $\begin{array}{l}\varnothing-i x-n o] \\
\text { I-get.up-PFV.CVB }\end{array}$ \\
\hline$b-u t^{\prime}-o$ & $Z O q^{\prime} \mathrm{e}-S$ & geni & ažey-x’o-s \\
\hline III-collect-IPFV.CVB & be-WPST & pear(III) & tree-SPR-ABL1 \\
\hline
\end{tabular}

Although there are no formal means of separating the various uses of $-n$ from each other (e.g. auxiliaries in periphrastic verb forms or enclitics in some complement clauses), there is at least a significant difference in meaning that separates the occurrences of $-n$ in the Simple Unwitnessed Past from all other occurrences of this suffix. This difference is due to evidentiality. When used as Simple Unwitnessed Past $-n$ combines past time reference with the evidentiality meaning unwitnessed. In contrast, when $-n$ is used in certain complement clauses without any enclitic it lacks both a temporal and an evidential value (15), (see (24b) in Section 4.3.1 for an example and its explanation). Similarly, in adverbial clauses it lacks evidentiality and expresses relative temporal meaning (simultaneity or anteriority). When $-n$ is used on the lexical verb for the formation of periphrastic verb forms (Table 4) it also lacks evidentiality, because evidentiality is expressed by the auxiliary and not by the lexical verb. For example, the lexical verb in the Pluperfect Witnessed Past has the suffix $-n$, but the whole clause has the evidentiality meaning of witnessed (9c).

\footnotetext{
${ }^{8}$ I thank the reviewers for helping me to clarify this point.
} 
Note that in Archi, another Nakh-Daghestanian language, the situation is almost identical, i.e. the same suffix occurs alone in an unwitnessed past function and as a converb, and in periphrastic verb forms (Tatevosov 2001). The same is true for the remaining four Tsezic languages (cf. van den Berg (1993) for Hunzib, Kibrik and Testelec (2004) for Bezhta and Khalilova (2009) for Khwarshi).

I suggest that the occurrence of $-n$ as Perfective converb represents its basic form from which the occurrence in the Simple Unwitnessed Past has evolved. This explanation is based on Tatevosov's (2001) account of Archi. The situation found in Hinuq, Archi and the other Tsezic languages is strikingly similar to a diachronic development found in Balkan languages like Bulgarian. In both Bulgarian and the Nakh-Daghestanian languages the presence/absence of the auxiliary has to do with the grammatical marking of epistemic information. In these languages the categories expressing evidentiality originate from a periphrastic construction with the verb 'be'. Thus, I propose the following diachronic development: first, $-n$ has been used in converb clauses with a perfective meaning. This use has been extended to independent clauses by adding the auxiliary 'be' to the converb, which led to periphrastic verb forms formally and functionally resembling perfects and pluperfects in other languages. One of the possible diachronic changes of periphrastic morphological forms is the loss of the auxiliary. At the same time the meaning of the former periphrastic verb form changed from perfect (or pluperfect) to unwitnessed past. In fact, the development of verb forms with evidential meaning from perfects is a crosslinguistically well-attested phenomenon in a number of unrelated languages such as Bulgarian, Macedonian, Turkish, Georgian, Udmurt, Inuit, Tucano and Tibetan languages (cf. Dahl 1985: 152-153, Bybee et al. 1994: 95-97).

\subsubsection{The Resultative participle $-s$}

The Resultative participle suffix $-s$ is used in four different clause types: (i) as Simple Witnessed Past in independent clauses (1d), (5b), (9a), (11b), (23), (24b), etc.; (ii) in periphrastic verb forms with resultative meaning (20a); in complement clauses together with an enclitic, e.g. with the Abstract enclitic (11b); and (iv) in relative clauses (20b).

\begin{tabular}{|c|c|c|c|c|c|}
\hline \multirow[t]{2}{*}{$(20 \mathrm{a})$} & $\begin{array}{l}\text { hoboži } \\
\text { now }\end{array}$ & $\begin{array}{l}o b u-S-n o \\
\text { father-GEN }\end{array}$ & 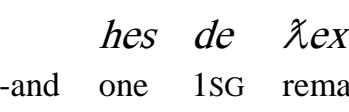 & $\begin{array}{ll}e-S & g o 1 \\
- \text { RES.PTCP } & \text { be }\end{array}$ & $\begin{array}{l}\text { hes } \\
\text { one }\end{array}$ \\
\hline & \multicolumn{5}{|c|}{ 'I am the only one remaining who the father still has.' } \\
\hline \multirow[t]{2}{*}{$(20 b)$} & $\begin{array}{l}\text { hayli } \\
\text { there }\end{array}$ & $\begin{array}{l}\text { maydan- } i \\
\text { glade-IN }\end{array}$ & $\begin{array}{l}r \text {-uhe-s-no } \\
\text { NHPL-die-RES.PTCP-and }\end{array}$ & $\begin{array}{l}\text { čaguyaw-no } \\
\text { alive-and }\end{array}$ & $\begin{array}{l}\text { ћaywan-be } \\
\text { animal-PL }\end{array}$ \\
\hline & $\begin{array}{l}\text { q'idi } \\
\text { down }\end{array}$ & \multicolumn{4}{|c|}{$\begin{array}{l}\chi e x w e-n \\
\text { remain-UWPST }\end{array}$} \\
\hline
\end{tabular}

Again the various uses can be distinguished on formal grounds (by means of auxiliaries or enclitics), or through a difference in meaning. The Simple Witnessed Past has past time reference and the evidentiality meaning witnessed, which is absent when this suffix occurs in periphrastic verb forms or relative clauses as in the examples $(20 \mathrm{a}, \mathrm{b})$ above. In contrast, when $-s$ is used in 
periphrastic verb forms and in relative clauses the suffix has usually a resultative meaning (20a) that is absent from its use in complement clauses or as Simple Witnessed Past.

Concerning the diachronic development, I propose that the use of $-s$ in dependent clauses was basic. Due to the adjectival nature of participles, they can be used in adjectival predication together with a copula, which explains the use of this participle in periphrastic verb forms. In this use its original resultative meaning has been preserved. In the course of time the copula has been deleted and the originally resultative verb form developed into a verb form expressing past time reference, a development that has also been observed for other languages (cf. Bybee et al. 1994, 68-69). Maybe in contrast to clauses with past time reference headed by the Perfective converb (Section 4.2.1) that refer to situations not witnessed by the speaker, the Resultative participle used in independent clauses acquired the evidentiality value 'witnessed'. For Akhvakh, another Nakh-Daghestanian language, Creissels (2009) has proposed a similar diachronic scenario.

\subsubsection{The Masdar}

In Caucasian linguistics the term Masdar refers to deverbal nouns that have both verbal and nominal properties. It is formed with the suffix $-n u$. With verbs that can take the Infinitive suffix the Masdar is formed by adding the suffix $-n u$ to the Infinitive. Verbs that lack the Infinitive add -nu directly to the stem, e.g. $\varnothing$-edor-nu from -edo:- 'work', or ga:-nu from ga:- 'drink'.

In Hinuq the Masdar behaves quite unusually. First, it can be used as the only predicate of an independent sentence with a negative semantics, referring to an event that is expected to happen, but has still not happened (21a). In these sentences the copula can be added. If the copula in the Present tense is added the meaning of the sentence does not change. Instead of the copula in the Present tense, the same verb with past time reference can be used (21b). However, the copula must be affirmative; it can never be used in its negated form.

(21a) [Context: The king is expected to arrive]

$\begin{array}{llll}\text { xan } & \text { žied } & \varnothing \text {-aq'-a-nu } & \text { (goł) } \\ \text { khan(I) } & \text { yet } & \text { I-come-INF-MSD } & \text { (be) }\end{array}$

'The king has not arrived yet.' (EL)

$\begin{array}{lllll}\text { obu-y } & \text { hoboži-n } & \text { rede } & b-u w-a-n u & \text { zoq'we-s } \\ \text { father-ERG } & \text { now-and } & \text { wood(III) } & \text { III-make-INF-MSD } & \text { be-WPST } \\ \text { 'Father had not yet prepared wood for the winter.' (EL) }\end{array}$

Second, the Masdar can be used in clauses that function and look like relative clauses. Again it has a negative semantics in these clauses (22).

$$
\begin{array}{llllll}
\text { hadu } & \text { got } & \text { [tetu } & y \text {-iy-a-nu }] & \check{S} a r-m o-s & \text { cen } \\
\text { this } & \text { be } & \text { cream(IV) } & \text { IV-take.away-INF-MSD } & \text { ball-OBL-GEN1 } & \text { quark }
\end{array}
$$

'This is round cottage cheese from which the cream has not been taken away.'

Third, the Masdar can take case suffixes. For example, it can function as the Genitive modifier of a noun (23). It can also occur in argument position of verbs, e.g. in example (14) of Section 3.5. 
In the nominal function the Masdar has only affirmative semantics; the case suffixes indicate its role in the clause.

$$
\begin{aligned}
& \text { Ø-iš-a-nu-zo moč-a hayłoy čay ga:-s } \\
& \text { I-eat-INF-MSD-GEN2 place.OBL-IN 3SG.MASC.ERG tea drink-WPST } \\
& \text { 'Instead of eating he drank tea.' (EL) }
\end{aligned}
$$

\subsection{Categories associated with finiteness}

As mentioned in Section 1.1, there is no accepted definition of finiteness. Instead, a number of categories and constructions have been proposed for the definition of finiteness or have been related to finiteness in one way or another. I will discuss the following categories and constructions that are relevant for Hinuq:

- tense

- evidentiality

- $\operatorname{mood}$

- aspect

- polarity

- gender/number agreement

- case marking of arguments

- overt subjects

- word order

- $\mathrm{CVB} / \mathrm{PTCP}$ markers, case marking on verbs

- clitics

Other categories that have been used for defining finiteness in other languages, e.g. person agreement or politeness, do not occur in Hinuq and will therefore not be taken into account.

\subsubsection{Tense and evidentiality}

All simple verb forms occurring in independent clauses express a temporal reference, i.e. they refer to some moment in the past, in the present or in the future. In addition, when used in independent main clauses verbs with the suffixes $-s$ and $-n$ have the evidentiality meanings witnessed and unwitnessed, respectively. In contrast, when these forms are used in dependent clauses they do not have their own temporal value and evidentiality, but get these values from the matrix verb. For example, the event that the verb form r-išer-ho in (24a) describes is interpreted as occurring in the past and being witnessed because the matrix verb carries the suffix - $s$ (Simple Witnessed Past). If $r$-išer-ho occurred in an independent clause it would have present time reference. Similarly, in (24b) the speaker must be a witness of the event described because the main verb has the Simple Witnessed Past suffix. In contrast to this, the sentence hayłoy t'ek tot'erno used as an independent main clause translates as 'He apparently read the book' with the evidentiality value unwitnessed. 


$\begin{array}{llll}\text { hayłoy } & \text { t'ek } & \text { t'ot'er-no } & \text { faq'er-iš } \\ \text { 3SG.MASC.ERG } & \text { book } & \text { read-PFV.CVB } & \text { finish-WPST }\end{array}$

'He finished reading the book.' (EL)

The verb forms used in adverbial clauses, but not in independent clauses (i.e. specialized converbs and three participles) lack evidentiality and absolute temporal reference. They express at most relative temporal reference, that is, temporal reference in relation to the situation described by the matrix verb, or no temporal reference at all. For example, the Terminative converb indicates that the action of the dependent clause marks the endpoint of the action of the main clause.

$$
\begin{aligned}
& \text { me sira [kwatizi y-iq-ače] גexwe-y-えen } \\
& \text { 2SG why be.late II-happen-TERM remain-WPST.Q-QUOT } \\
& \text { 'Why did you remain till you were late?' }
\end{aligned}
$$

\subsubsection{Mood and aspect}

Many mood and aspect values carry over from main clauses to subordinate clauses. Nonindicative moods such as the Imperative and the Optative occur also in indirect speech contexts:

$$
\begin{array}{lll}
\text { [xec-o } & \text { de-Xen] } & \text { exi-yo } \\
\text { let-IMP } & 1 \mathrm{SG}-\mathrm{QUOT} & \text { say-PRS }
\end{array}
$$

'He says, let me.'

Another non-indicative mood, the Irrealis conditional, can be formed from (almost) all TAM forms that also occur in independent clauses. ${ }^{9}$ Only in the apodosis of Irrealis conditional clauses is the occurrence of TAM forms restricted to the General Tense or the Future in the Past forms.

The aspectual values of many verb forms used in subordinate clauses are unspecified. But there are two participles that clearly have the aspectual values of resultative and habitual, which carry over to the periphrastic TAM forms that are built up from them. In the same vein, all periphrastic TAM forms containing the Imperfective converb have the aspectual value 'imperfective'. Consequently, main clauses and dependent clauses that contain these participles and converbs express the same aspectual values.

In Hinuq one can build periphrastic verb forms not only with the auxiliaries got 'be' and $z o q$ 'we- 'be', but also with the light verb -ič $i$ - 'be' (27a). These constructions refer to ongoing events which do not have a result or whose results are not important. Similar constructions with the same light verb are available in adverbial subordination, and they have the same aspectual meaning of progressive (27b).

$$
\begin{aligned}
& \text { sasaqo nesa t'ek t'ot'er-ho Ø-iči-yo zoq'we-s } \\
& \text { morning evening book read-IPFV.CVB I-be-IPFV.CVB be-WPST } \\
& \text { 'In the morning, in the evening I (masc.) was reading books.' }
\end{aligned}
$$

\footnotetext{
${ }^{9}$ This refers to the clauses formed with the Irrealis particle $q$ 'ede (Section 3.2.1).
} 


$$
\begin{aligned}
& \text { [Ø-iði-yo Ø-iči-n] hayłoz đ'oq'ar kezi.y.iqqo ked } \\
& \text { I-go-IPFV.CVB I-be-PFV.CVB 3SG.MASC.DAT towards meet.II.PRS girl(II) } \\
& \text { 'While he is going, he meets a girl.' }
\end{aligned}
$$

\subsubsection{Polarity}

Not all simple verb forms occurring in independent clauses can express negative polarity (see Table 3 in Section 2.2). In addition, three forms contain a negative marker that differs synchronically from the standard negative marker $-m e$.

Periphrastic verb forms can be negated by negating the auxiliary. The only exceptions are forms built with the Masdar. These forms are inherently negative in their semantics and therefore do not allow the use of a negated auxiliary.

All participles have a negative counterpart whereas the Infinitive and the majority of the converbs occur only with affirmative meaning.

\subsubsection{Agreement and case assignment}

All verb forms follow the same rules for gender and number agreement: they agree with the Absolutive argument of their clause. If the position of the Absolutive argument has been filled by a clause then the matrix verb takes either the agreement prefix $r$ - (gender V) or they agree with the Absolutive argument of the embedded clause. The first possibility, called 'plain local agreement' by Polinsky and Potsdam (2001) has been exemplified in (12c) and (13) of Section 3.5. The second possibility can be seen in (28) and is called 'long distance agreement'.

$$
\begin{array}{llllll}
\text { obu-z } & \text { b-eq'i-yo } & \text { [Pat'imat } & \text { iyoz } & \text { kumak } & \text { b-ul'-x'os-Hi] } \\
\text { father-DAT } & \text { III-know-PRS } & \text { Patimat } & \text { motherDAt } & \text { help(III) } & \text { III-do-HAB.PTCP-ABST } \\
\text { 'The father knows that Patimat will help the mother.' (EL) }
\end{array}
$$

If the Absolutive argument of the matrix clause is realized overtly only in the embedded clause then the matrix verb nevertheless agrees with this argument, independently of the role (and the case) that the argument has in the embedded clause (29a). This phenomenon has been called "Backward control" by Polinsky and Potsdam (2002). Similarly, if the Absolutive argument of the embedded clause is realized overtly only in the main clause then the embedded verb agrees with this argument independently of the role (and the case) that the argument has in the main clause. This can be observed with relative clauses whose head function as the Absolutive argument of their relative clause, but occur in a different position (e.g. agent or recipient) in the matrix clause $(29 b)$.

$$
\begin{aligned}
& \text { [ked-i uŽi } \quad \text { zok'-a] } \quad y \text {-ułi-š } \\
& \text { girl(II)-ERG boy beat-INF II-begin-WPST } \\
& \text { 'The girl began to beat the boy.' (EL) }
\end{aligned}
$$

$$
\begin{array}{lllllll}
\text { [uŽi-Ž } & y \text {-eti-yo } & \text { goła] } & \text { ked-i } & \text { r-egi } & \text { xok'o-be } & r \text {-li-ho } \\
\text { boy-DAT } & \text { II-want-IPFV.CVB } & \text { be.PTCP } & \text { girl(II)-ERG } & \text { NPL-good } & \text { khinkal-PL } & \text { NPL-make-PRS }
\end{array}
$$

'The girl who the boy loves makes good khinkal.' (EL) 
Verb forms follow the same case assignment patterns in all clause types. In other words, arguments in dependent clauses get the same cases assigned as arguments in independent clauses.

If a clause headed by a nominalized verb form occurs in argument position of a verb the entire clause gets the same case assigned that a lexical noun would get. For example, arguments of the verbs boži -iq- 'believe' and šak-iq- 'doubt' must take the Super-Essive case suffix (14).

\subsubsection{Overt subject and word order}

Dependent clauses can have their own overtly expressed subject which is in the case required by the verb, that is, in the Absolutive in case of intransitive verbs, in the Ergative in case of transitive verbs and in the Dative in case of experiencer verbs. This is true for all verb forms occurring in dependent clauses. Examples are (11a, b), (12b), (18) and the first dependent clause in $(24 a)$.

Only a minority of complement taking verbs take exclusively Infinitive/ Purposive converb complements, which require the identity of main clause and dependent clause subject, e.g. the modal verbs $k$ 'wezi -iq- and kox'e- 'be able' (12b) and the phasal verbs baybik -ui- and -uti(29a) 'begin'. The phasal verbs łaq'e- (intr.) and faq'er- (trans.) 'finish', 'end' take only verbs marked with the Narrative converb suffix as complements, which also require the identity of main clause and dependent clause subject (15), (24b).

In case of identical subjects commonly equi-deletion occurs: only one of the subjects is overtly expressed, mostly the main clause subject (8b), (27b), but occasionally also in the embedded clause (29a). However, it seems that equi-deletion in complement clauses is not obligatory, not even in case of identity of main clause and embedded clause subject (12b).

Converb constructions allow overt identical subjects in the main and the adverbial clause if one of the overt arguments is a reflexive pronoun (30). However, these constructions are marginal and hardly ever attested in texts. In general, coreferential arguments are deleted.

$\begin{array}{lllll}\text { Palí } & \text { konfetbe } & \text { r-aq'er-ho } & \text { [zo } & \text { Ø-aq'e-yo] } \\ \text { Ali.ERG } & \text { sweets } & \text { NPL-bring-PRS } & \text { REFL.SG } & \text { I-come-COND } \\ \text { 'If he }{ }_{i} \text { comes Ali }{ }_{i} \text { brings sweets.' } & \text { (EL) } & \end{array}$

To sum up, there is no verb form that obligatorily requires the deletion of an overt subject. Even embedded clauses headed by an Infinitive can have an overtly expressed subject.

In both dependent and independent clauses the preferred order is SOV. Other orders are possible, but dependent clauses are almost exclusively verb-final. Relative clauses even prohibit any word order other then verb-final.

\subsubsection{Verb forms and clitics used in subordinate clauses}

Case-marking on verbs and special verb forms only used in dependent clauses are properties associated with nonfiniteness. Hinuq has a number of specialized converbs and two participles that are only used in dependent clauses (see groups (iv) and (v) in Section 4.1).

Synchronically at least the Posterior, the Simple Anterior and the Purposive converb clearly contain case suffixes. The Posterior converb contains the Lative marker $-r$, the Simple Anterior 
converb contains the Genitive/Ablative marker $-s$, and the Purposive converb the Dative marker $z$. Arguably, the suffix $-\chi$ 'o that is found in both the Posterior and the First Simultaneous converb is synchronically the Super-Essive marker, with which it is homophonous.

Furthermore, case suffixes can be added to the participles and the Masdar in order to use them in adverbial clauses (17) or complement clauses (14).

Hinuq uses two enclitics to mark certain forms of subordination: the Abstract enclitic - $f i$ and the Quotative enclitic - $\chi$ en. The former enclitic occurs on the Resultative and on the Habitual participle when they are used in complement clauses of knowledge predicates (11b), (13) and (28). The latter enclitic occurs on all verb forms used in complements of certain psych verbs (11a).

\section{Conclusion}

The morphological categories that are most often employed when referring to finite vs. nonfinite verbs are tense and agreement inflection. As emphasized in Section 4.3.4, the agreement properties of Hinuq verb forms do not differ from each other, that is, all verbal forms behave alike.

As for tense, the situation is more complicated. There are a number of suffixes that occur on verbs that are the only predicate of an independent clause, on verbs that are used in combination with auxiliaries as the predicate of an independent clause, and on verbs occurring as predicates of dependent clauses. Their temporal interpretation varies depending on the predicate/clause type (Section 4.2.1). But there are also a number of verb forms that occur only in one predicate/clause type. For instance, specialized converbal forms do not contain TAM suffixes and as a result do not carry information about the absolute temporal reference of their clause. Following Bisang's terminology the converbs and participles exemplify the "minus-strategy".

Another inflectional category of verbs, overt polarity, is present in most but not all verb forms that head independent clauses. That is, two TAM forms occurring in independent clauses lack a negative counterpart, but they can be negated by using other TAM forms. For many specialized converbs used in dependent clauses the situation is even worse: they do not only lack a negative form, but they can not be replaced by other negative converbs. In other words, polarity does not help us very much to distinguish clauses or constructions from each other with respect to their finiteness. This is in accordance with Givón's (1990) finiteness-scale of TAM presented in Figure 1 of Section 1.1, which states that polarity is if at all a weak indicator for finiteness.

All these facts lead to the conclusion that finiteness cannot be used to describe the morphological property of a verbal suffix or a verb form in Hinuq. Similarly, dependent and independent clauses do not usually differ in their syntactic properties. There are no dependent clauses that ban the occurrence of overt subjects, and only relative clauses have strict verb-final word order.

Therefore, I will adopt Givón's (1990) concept of finiteness as conformity or deviation from the independent clause pattern (Section 1.1) and order the verbal suffixes of the six groups (Section 4.1) along the following scale: 
independent clauses • suffixes that occur only in independent clauses (i), (ii)

- suffixes in periphrastic verb forms of independent clauses, and in dependent clauses (ii), (iii), (vi)

dependent clauses $\quad$ specialized converbs and participles used only in dependent clauses (iv), (v)

To the suffixes occurring only in independent clauses belong not only all four suffixes of group (ii), but also suffixes of group (ii) when they are used without any further auxiliary. To the next group, the suffixes used in periphrastic verb forms and as heads of dependent clauses, belong all suffixes of the groups (iii) and (vi), but also the suffixes of group (ii). The last group contains only specialized converbs (iv) and two participles (v) occurring exclusively in dependent clauses.

Clauses formed with the help of suffixes occurring only in independent clauses can be called "finite". In contrast, clauses formed with specialized converbs and participles occurring only in dependent clauses can be called "non-finite". The third group of suffixes can be ranked somewhere in between the two extremes.

Now, the problem is that suffixes of group (ii) belong to two different groups at the same time since they can occur in independent and in dependent clauses. Sometimes there are obvious formal differences between the uses of group (ii) suffixes in independent and in dependent clauses such as additional auxiliaries for periphrastic verb forms in independent clauses, the participle goła in relative clauses or Masdars with case suffixes in complement clauses. Sometimes there is an obvious semantic difference distinguishing the occurrences of group (ii) suffixes in independent clauses from their occurrences in dependent clauses (time reference, evidentiality, affirmative vs. negative meaning). Complement clauses with enclitics or in the Irrealis conditional mood represent somewhat intermediate stages because they often contain TAM forms of independent clauses, but additionally markers that indicate that these clauses are dependent. For example, the Abstract enclitic can be interpreted as a kind of nominalization marker that forms abstract nouns not only from other nouns or adjectives, but also from clauses. The question remains open whether these clauses should be called "finite" because they contain TAM forms otherwise restricted to independent clauses, or "nonfinite" because of the extra enclitics and particles.

Still there are two clause types that do not really fit into the above scale. Independent clauses without any overt verb (3.1 and 3.4) apparently differ from the prototype transitive main clauses.

To sum up, it is possible to set out indisputable independent and indisputable dependent clauses in Hinuq, but there are some clause types in between that differ in a variety of ways from the extremes. Finiteness as a morphological category of the verb has been proven to be useless for Hinuq since one and the same suffixes occur in dependent and independent clauses.

\section{Abbreviations}

I - V gender classes ABL1 first Ablative ABST Abstract ALOC 'animate' location ANTIP antipassive AT location 'at' CAUS causative CONC concessive converb COND conditional converb CVB converb DAT Dative DIR Directional ERG Ergative GEN1 first Genitive GEN2 second Genitive GT General tense HAB habitual HPL human plural ILOC 'inanimate' location IN location 'in(side)' INF infinitive INFUT Intentional future IMP 
imperative IPFV imperfective IRR Irrealis LAT Lative MSD masdar NEG negation NPL nonhuman plural OBL oblique PFV perfective PL plural POT potential PROH prohibitive PRS present PST past PTCP participle PURP Purposive converb Q question QUOT quotative REFL reflexive RES resultative SG singular SIM simultaneous converb SPR location 'on' SUB location 'under' TERM Terminative converb UWPST Unwitnessed past WPST Witnessed past

\section{References}

Bisang, Walther. 2001. Finite vs. non finite languages. Language typology and language universals, vol. 2, ed. by Martin Haspelmath, Ekkehard König, Wulf Oesterreicher and Wolfgang Raible, 1400-1423. Berlin: Mouton de Gruyter.

-----. 2007. Categories that make finiteness: discreteness from a functional perspective and some of its repercussions. Finiteness: Theoretical and empirical foundations, ed. by Irina Nikolaeva, 115-137. Oxford: Oxford University Press.

Bybee, Joan, Revere Perkins, and William Pagliuca. 1994. The evolution of grammar: Tense, aspect, and modality in the languages of the world. Chicago: The University of Chicago Press.

Creissels, Denis. 2009. Participles and finiteness: The case of Akhvakh'. Linguistic Discovery 7.1. 106-130.

Cristofaro, Sonia. 2007. Deconstructing categories: finiteness in a functional-typological perspective. Finiteness: Theoretical and empirical foundations, ed. by Irina Nikolaeva, 91114. Oxford: Oxford University Press.

Dahl, Östen. 1985. Tense and aspect systems. Oxford: Blackwell.

Eisenberg, Peter et.al. 1998. Duden Grammatik der deutschen Gegenwartssprache. Mannheim: Dudenverlag.

Evans, Nicholas. 2007. Insubordination and its uses. Finiteness: Theoretical and empirical foundations, ed. by Irina Nikolaeva, 366-431. Oxford: Oxford University Press.

Givón, Talmy. 1990. Syntax: A functional-typological introduction, vol. 2. Amsterdam: Benjamins.

Haspelmath, Martin. 1993. A grammar of Lezgian. Berlin: Mouton de Gruyter.

Kalinina, Elena Ju. 2001. Nefinitnye skazuemye v nezavisimom predloženii [Nonfinite predicates in independent clauses]. Moscow: IMLI RAN.

Kalinina, Elena and Nina Sumbatova. 2007. Clause structure and verbal forms in NakhDaghestanian. Finiteness: Theoretical and empirical foundations, ed. by Irina Nikolaeva, 183 - 249. Oxford: Oxford University Press.

Khalilova, Zaira. 2009. A grammar of Khwarshi. Utrecht: LOT.

Kibrik, Aleksandr E. and Testelec, Jakov G. 2004. Bezhta. The indigenous languages of the Caucasus Vol. 3: The North East Caucasian languages, Part 1, ed. by Michael Job, 217 - 295. New York: Caravan Books.

Koptjevskaja-Tamm, Maria. 2009. Review of "Finiteness." Folia Linguistica 43(1), 213-249.

Maas, Utz. 2004. "Finite" and "nonfinite" from a typological perspective. Linguistics 42(2): 359385.

Nikolaeva, Irina. 2007a. Introduction. Finiteness: Theoretical and empirical foundations, ed. by Irina Nikolaeva, 1-19. Oxford: Oxford University Press. 
Nikolaeva, Irina (ed.) 2007b. Finiteness: Theoretical and empirical foundations. Oxford: Oxford University Press.

Payne, Thomas E. 1997. Describing morphosyntax. Cambridge: Cambridge University Press.

Polinsky, Maria and Eric Potsdam. 2001. Long-distance agreement and topic in Tsez. Natural Language \& Linguistic Theory 19, 583-646.

----. 2002. Backward control. Linguistic Inquiry 33(2), 245-282.

Sells, Peter. 2007. Finiteness in non-transformational syntactic frameworks. Finiteness: Theoretical and empirical foundations, ed. by Irina Nikolaeva, 59-88. Oxford: Oxford University Press.

Tatevosov, Sergei. 2001. From resultatives to evidentials: Multiple uses of the perfect in NakhDaghestanian languages. Journal of Pragmatics 33, 443-464.

van den Berg, Helma. 1995. A Grammar of Hunzib (with texts and lexicon). Munich: Lincom Europa.

Author's Contact Information:

Diana Forker

Bamberg University

diana.forker@uni-bamberg.de 